\title{
PIMAS
}

Jurnal Pengabdian Masyarakat

Homepage: http://ejournal.uhb.ac.id/index.php/PIMAS

\section{Pelatihan Penulisan Artikel Ilmiah dengan Menggunakan Tips dan Trik Pengoptimalan Teknologi}

\author{
Khoirun Nisa ${ }^{1}$, Purwono ${ }^{2}$, Novita Ranti Muntiari ${ }^{3}$ \\ 1,2,3 Universitas Harapan Bangsa, Jl. Raden Patah No. 100 Kedunglongsir, Ledug, Kembaran, Banyumas 53182, Jawa Tengah \\ 1'khoirunnisa@uhb.ac.id; ${ }^{2}$ purwono@uhb.ac.id; ${ }^{3}$ novitaranti@uhb.ac.id
}

Artikel History:

Received: 03-02-2022 / Received in revised form: 05-02-2022 / Accepted: 07-02-2022

\begin{abstract}
Publications have an important role in the world of education, both for lectures and students. Based on two points of view, the first is from educators that scientific publications are the main indicators of academic performance. Research results are meaningless without a publication, whether published in online media or in print media. While the second, seen from students that making publications in several universities is a requirement to achieve a graduation. Therefore, the devotees carry out community service on "Scientific Article Writing Training Using Technology Optimization Tips and Tricks". This service goes through several stages, namely analysis, problem determination, solution and evaluation. This training is delivered with material presentation, practice and panel discussion. This activity received a very satisfied response by the participants, as seen from the calculation of correspondents distributed by the team, the average was $87.78 \%$ and those who expressed satisfaction were $12.2 \%$.
\end{abstract}

Key words : Webinars, Publications, Lecturers, Students

\begin{abstract}
ABSTRAK
Publikasi mempunyai peranan penting dalam dunia pendidikan, bagi tenaga pengajar maupun mahasiswa. Berdasarkan dua sudut pandang, yang pertama dari tenaga pendidik bahwa Publikasi ilmiah menjadi indikator utama kinerja akademik, Hasil penelitian tidak berarti tanpa adanya suatu publikasi, baik dipublikasikan di media online maupun di media cetak. Sedangkan yang kedua, dilihat dari mahasiswa bahwa membuat publikasi dibeberapa perguruan tinggi merupakan syarat untuk mencapai sebuah kelulusan. Oleh karena itu, pengabdi melakukan pengabdian masyarat tentang "Pelatihan Penulisan Artikel Ilmiah dengan Menggunakan Tips dan Trik Pengoptimalan Teknologi”. Pengabdian ini melalui beberapa tahapan yaitu analisis, penentuan permasalahan, solusi dan evaluasi. Pelatihan ini disampaikan dengan pemaparan materi, praktek dan diskusi panel. Kegiatan ini mendapat respon sangat puas oleh peserta dilihat dari perhitungan koresponden yang disebarkan oleh tim ratarata yaitu $87,78 \%$ dan yang menyatakan puas sebesar $12,2 \%$.
\end{abstract}

Kata kunci : Webinar, Publikasi, Tenaga Pengajar, Mahasiswa

\section{PENDAhuluan}

Publikasi memiliki peranan penting dalam dunia pendidikan, bagi tenaga pengajar maupun mahasiswa. Berdasarkan sudut pandang seorang tenaga pendidik, Publikasi ilmiah menjadi indikator utama kinerja akademik, Hasil dari penelitian tidak berarti tanpa publikasi, baik dipublikasikan di media

*Corresponding author. Tel.: +62 821-3897-8212

Email:khirunnisa@uhb.ac.id 
online maupun di media cetak lainnya. Sedangkan dilihat dari sudut padang mahasiswa membuat publikasi dibeberapa perguruan tinggi merupakan syarat untuk mencapai sebuah kelulusan.

Publikasi ilmiah yang dimaksud disini adalah publikasi artikel penelitian jurnal nasional atau internasional secara online atau berdasarkan OJS (open journal system). Publikasi ilmiah merupakan bagian dari hasil penelitian, publikasi baik mulai dari pilihan kualitas jurnal, kualitas Jurnal dapat dicirikan oleh jurnal yang terindeks seperti Google Scholar, DOAJ, Scopus, jurnal terakreditasi nasional atau internasional sesuai dengan ketentuan penyusunan jurnal dan menghindari predator. Banyak jurnal predator bermunculan belakangan ini, yang biasanya jurnal OJS asing, menawarkan kemudahan publikasi dengan biaya rendah. Tentu hal tersebut harus diperhatikan agar tidak terjebak dalam pemilihan publikasi. Hal ini bisa dilihat dari segi kualitas jurnal melalui scimago, selanjutnya pencarian referensi yang Sebagian besar dari Pustaka primer seperti jurnal ilmiah dan prosiding, contohnya menelusuri melalui google scholar, doaj, scopus atau indeksing lainnya yang menyimpan ratusan bahkan ribuan judul jurnal yang bereputasi (Darmalaksana \& Suryana, 2018).

Menulis artikel di jurnal harus memiliki keahlian khusus untuk menyelesaikan setiap paragraf dan kemudian menjadi artikel yang siap diterbitkan. Seperti hal nya dalam menulis skripsi, tesis, serta disertasi, memiliki persyaratan teknis untuk menulis. Bentuk publikasi yang berfungsi untuk merekam kegiatan akademik, mengesahkan hasil kegiatan yang memenuhi persyaratan ilmiah minimal, menyebarluaskan kepada masyarakat umum, dan mengarsipkan semua hasil kegiatan akademik maupun kecendekiaan ilmuwan yang dimuat (Butsi \& Nasution, 2017).

Biasanya, jurnal dilengkapi dengan template seperti aturan, kaidah, dan cara penulisan sehingga menjadi artikel yang lengkap sesuai dengan gaya penulisan jurnal tersebut. Tujuan publikasi hasil penelitian yang menjadi titik tekan pemerintah akhir-akhir ini adalah kewajiban bagi tenaga pengajar untuk mempublikasikan hasil penelitiannya pada jurnal terindeks Scopus atau jurnal internasional yang bereputasi dengan bercirikan Q1, Q2, Q3 dan Q4 sebagai Salah satu exit target yang ingin dicapai perguruan tinggi menuju world class university adalah banyaknya publikasi ilmiah dalam jurnal dan banyaknya jurnal yang digunakan oleh para akademisi lain yang mengutip hasil Salah satu cara efektif untuk menyebarluaskan jurnal saat ini adalah melalui jurnal elektronik (e journal) (Pribadi \& Delfy, 2015).

Penelitian yang berorientasi pada hasil merupakan penghubung yang terintegrasi antara input, output, outcome, manfaat, dan dampak. Integrasi ini bertujuan untuk meningkatkan kualitas dan mutu penelitian. Dalam konteks Indonesia, penelitian berbasis hasil merupakan kebijakan bercabang dua, yaitu substansi dan administrasi. harus melibatkan penjaminan mutu guna meningkatkan mutu penelitian. Penelitian yang berkualitas adalah yang menghasilkan keluaran, Outcome, manfaat dan dampak. Kebijakan penelitian yang sentral di Indonesia mengarahkan semua lembaga akademik untuk meningkatkan mutu dan kualitas penelitian, substansi dan administrasi (Darmalaksana, 2017). Sehingga dalam mewujudkan kearah sana maka perlu mempersiapkan naskah yang baik, pengolahan jurnal professional dan mekanisme diseminasi yang efektif dari jurnal tersebut. Karya ilmiah yang dipublikasikan adalah kontribusi pemikiran dalam menjawab berbagai permasalahan yang terjadi pada kehidupan manusia (Rohmah \& Huda, 2016)

Kualitas akademik dan sumber daya manusia diukur berdasarkan publikasi ilmiah yang dipublikasikan. Artikel ilmiah yang diterbitkan secara internasional, dibaca di seluruh dunia dan diindeks oleh database yang valid dan diakui akan membawa nilai tambah bagi lembaga pendidikan (terutama kurikulum), guru, siswa dan siswa tua. , baik profesor maupun non-profesor, tidak dapat dianggap memiliki bukti yang sah sebagai profesional di bidangnya jika tidak memiliki publikasi ilmiah, mereka memberikan kontribusi ilmiah di tingkat internasional melalui publikasi internasional, oleh karena itu, bahan ajar tampaknya ketinggalan zaman dan jika itu membimbing siswa, guru akan bergantung pada kemampuan siswa, dan siswa yang tidak kompetitif akan menghasilkan karya ilmiah secara lokal, akhirnya dapat dikatakan bahwa alumni adalah a Selain itu, karya ilmiah yang dihasilkan cenderung mengulang karya orang lain, meniru dan melanggar etika, atau untuk melakukan tindakan yang tidak terpuji atau plagiarism (Nasution, 2016).

Di era masyarakat ini, perguruan tinggi perlu memikirkan keterampilan lulusannya agar dapat bersaing dengan alumni dari negara lain. Tenaga pengajar sudah waktunya mempunyai kemandirian 
melalui publikasi ditingkat internasional sebagai dosen penulis pertama. Sehingga bisa memberikan pengetahuan dengan baik kepada mahasiswa sebagai dosen pembimbing, agar bisa memberikan kontribusi kepada bidang keilmuan dan program studi.

Adapun beberapa penelitian tentang kegiatan masyarakat yang berhubungan dengan pelatihan penulisan karya ilmiah. Penelitian pertama ditulis oleh Fitria (2021) menyatakan bahwa pelatihan penulisan artikel ilmiah bertujuan supaya para mahasiswa dapat mempersiapkan diri dalam penulisan artikel untuk dipublikasikan ke jurnal ilmiah nasional. Penelitian kedua, Udil (2021) menyatakan bahwa pelatihan penulisan artikel ilmiah PTK untuk publikasi pada jurnal ilmiah dapat meningkatkan pemahaman dan kemampuan, serta ketrampilan dalam membuat artikel yang layak dipublikasikan.Penelitian ketiga oleh Ginting et al. (2021) bertujuan untuk memberikan pelatihan kepada mahasiswa tingkat IV untuk dapat menulis artikel ilmiah dan melakukan publikasi dengan baik. Penelitian keempat dilakukan oleh Harahap \& Yunita (2021) menyatakan bahwa pelatihan bertujuan agar peserta bisa menulis artikel untuk jurnal nasional dan internasional.

Berdasarkan paparan diatas, pengabdian masyarakat ini mengambil topik yang berjudul "Pelatihan Penulisan Artikel Ilmiah dengan Menggunakan Tips dan Trik pada Pengoptimalan Teknologi". Pelatihan ini efektif untuk memberikan ilmu tentang kemudahana dalam menghadapi tantangan publikasi hasil penelitian di jurnal ilmiah. Sehingga memberikan trigger bagi mahasiswa dan tenaga pengajar dalam membuat sebuah publikasi ilmiah.

\section{METODE PELAKSANAAN KEGIATAN}

Pelaksanaan kegiatan ini dirancang dengan sebaik mungkin agar berjalan lancar sesuai yang diharapkan. Persiapan awal yang harus dilakukan adalah melakukan tinjauan terhadapa khalayak sasaran dari pengabdian ini adalah dimana targetnya tenaga pengajar dan mahasiswa. Setelah itu, Melakukan pengajuan kegiatan dari program studi kemudian mengkoordinasi dengan Lembaga Penelitian dan Pengabdian Kepada Masyarat (LPPM) Universitas Harapan Bangsa. LPPM UHB memberikan bantuan dengan memberikan fasilitas yang berhubungan dengan kegiatan administratif yang menunjang kelancaran pengabdian.

Selanjutnya menyiapkan materi, aplikasi dan peralatan yang akan digunakan dalam pelatihan nantinya. Pelaksanaan pelatihan mengunakan dua cara yaitu pemaparan materi dan praktek penulisan artikel ilmiah. Pendekatan yang digunakan dalam pelatihan ini dilakukan melalui zoom meeting. Adapun metode yang digunakan untuk pengabdian ini dapat dilihat pada gambar 1, tahapan tahapannya adalah sebagai berikut.

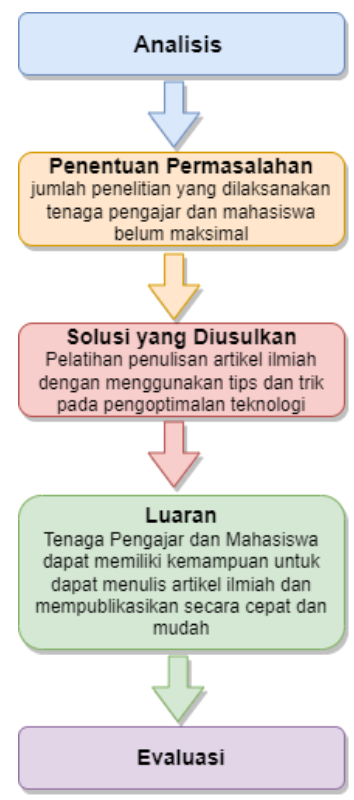

Gambar 1. Tahapan Metode yang Digunakan 


\subsection{Analisis}

Tahapan ini adalah tahap awal yang dilaksanakan sebelum melakukan kegiatan. Pada tahap ini analisis dilakukan kepada mitra terkait dengan kondisi saat ini terjadi dan terdapat beberapa masalah yang dihadapi.

2.2. Penentuan Permasalahan

Berdasarkan hasil analisis ditemukan permasalahan terkait jumlah penulisan artikel ilmiah sehingga memerlukan sebuah solusi untuk dapat menyelesaikannya.

2.3. Solusi yang Diusulkan

Pada tahap ini adalah penentuan solusi yang diusulkan oleh pengabdi yaitu melakukan pelatihan penulisan artikel ilmiah dengan triks dan tips untuk meningkatkan jumlah publikasi ilmiah yang diharapkan.

2.4. Luaran

Target dari pengabdian ini adalah tenaga pengajar dan mahasiswa dapat memiliki kemampuan untuk menulis artikel ilmiah dengan mudah dan cepat sehingga mampu meningkatkan jumlah publikasi ilmiah baik nasional dan internasional.

2.5. Evaluasi

Kegiatan Pengabdian ini perlu dilakukan evaluasi untuk mengukur sejauh mana tingkat keberhasilan pelaksanaan ini. Tahap ini diharapkan dapat mensinkronkan antara tujuan dan luaran dari kegiatan pengabdian. Tahap evaluasi mengacu pada perhitungan prosentasi dengan skala likert.

\section{HASIL KEGIATAN DAN PEMBAHASAN}

3.1. Pelaksanaan Kegiatan

Kegiatan pelatihan dilaksanakan pada hari senin, 25 Oktober 2021 Rundown acara dapat dilihat pada tabel 1 dimulai dari pembukaan oleh moderator hingga penutup. Kegiatan ini dihadiri kurang lebih 30 peserta dari mahasiswa hingga tenaga pengajar memal.

Tabel 1. Rundown Acara

\begin{tabular}{ccc}
\hline NO & WAKTU & KEGIATAN \\
\hline 1 & $12.30-12.45$ & Join Panitia \\
\hline 2 & $13.00-13.10$ & Join Participant \\
\hline 3 & $13.10-13.15$ & Pembukaan Host \\
\hline 6 & $13.15-13.25$ & Sambutan Dekan FST (Anggit Wirasto, S.Si., M.Eng.) \\
\hline 8 & $13.25-13.30$ & Penyampaian CV pembicara \\
\hline 9 & $13.30-14.30$ & Penyampaian \\
\hline 12 & $14.30-14.50$ & Materi + Praktek (Purwono, S.Kom., M.Kom.) \\
\hline 13 & $14.50-15.00$ & Diskusi Panel \\
\hline
\end{tabular}

Kegiatan diawali dengan sambutan oleh Anggit Wirasto, S.Si., M.Eng. selaku Dekan Fakultas Sains dan Teknologi, Universitas Harapan Bangsa. Kemudian dilanjutkan dengan pemaparan materi yang disampaikan oleh Purwono, S.Kom., M.Kom. selaku dosen Informatika UHB. Kegiatan ini dilaksanakan secara daring melalui zoom meeting dapat terlihat pada gambar 2 antusias peserta yang mengikuti pelatihan. 


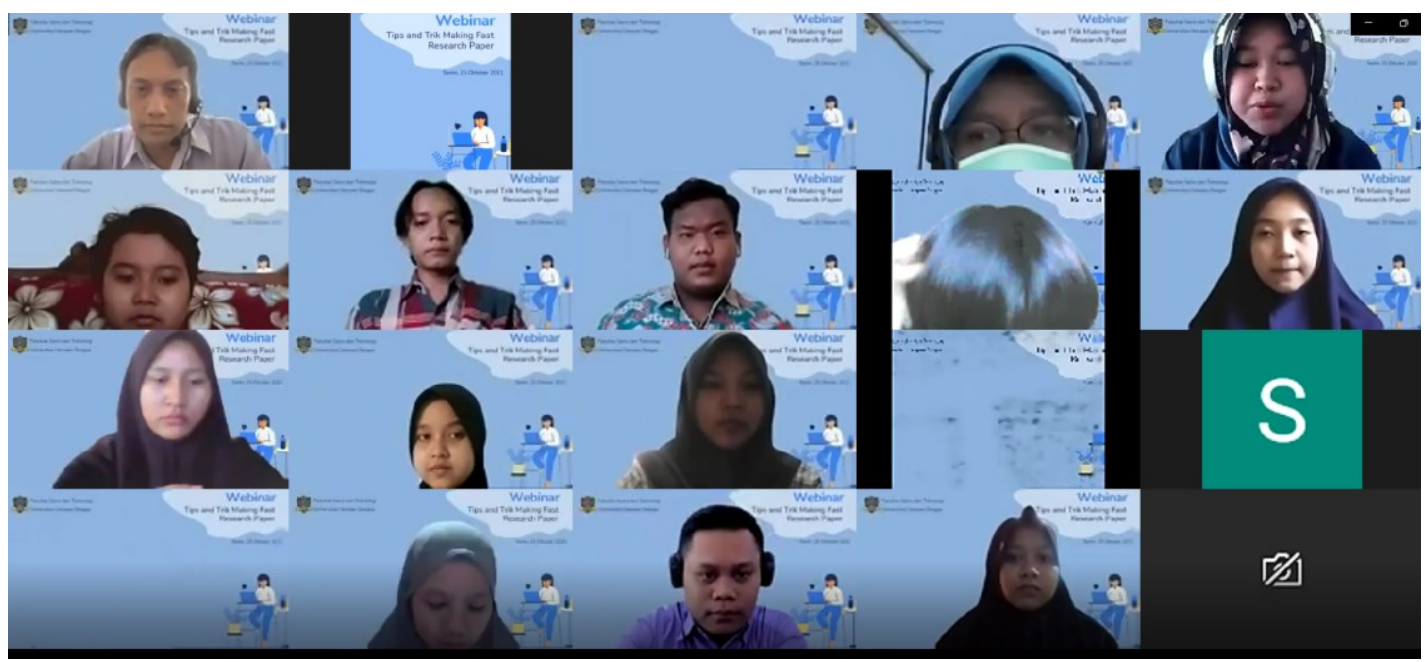

Gambar 2. Peserta Pelatihan melalui Zoom

Beliau menyampaikan tentang bagaimana cara memilih topik dengan beberapa referensi yang disediakan. Peralatan yang digunakan dalam menulis artikel seperti word, excel, draw.io, Mendeley, Grammarly, dan Turnitin. Selanjutnya tentang cara memilih target journal yang digunakan untuk publikasi, misalnya : apakah editorial fast respon, lalu cek waktu terbit jurnal tersebut, cek acceptance rate, dan pahami author guidelines. Beliau menggunakan IMRAD sebagai acuan dalam merincikan jurnal (Introduction, Materials and Methods, Discussion, dan Result). Kegiatan ini berjalan dengan sangat interaktif mulai dari penyampaian materi hingga melakukan praktek dapat dilihat pada gambar 3. Para peserta banyak memberikan pertanyaan dan konfirmasi kepada pengabdi terutama permasalahan Ketika mencari topik dan konfirmasi kepada pengabdi terutama saat memasukkan karya ilmiah di jurnal online.

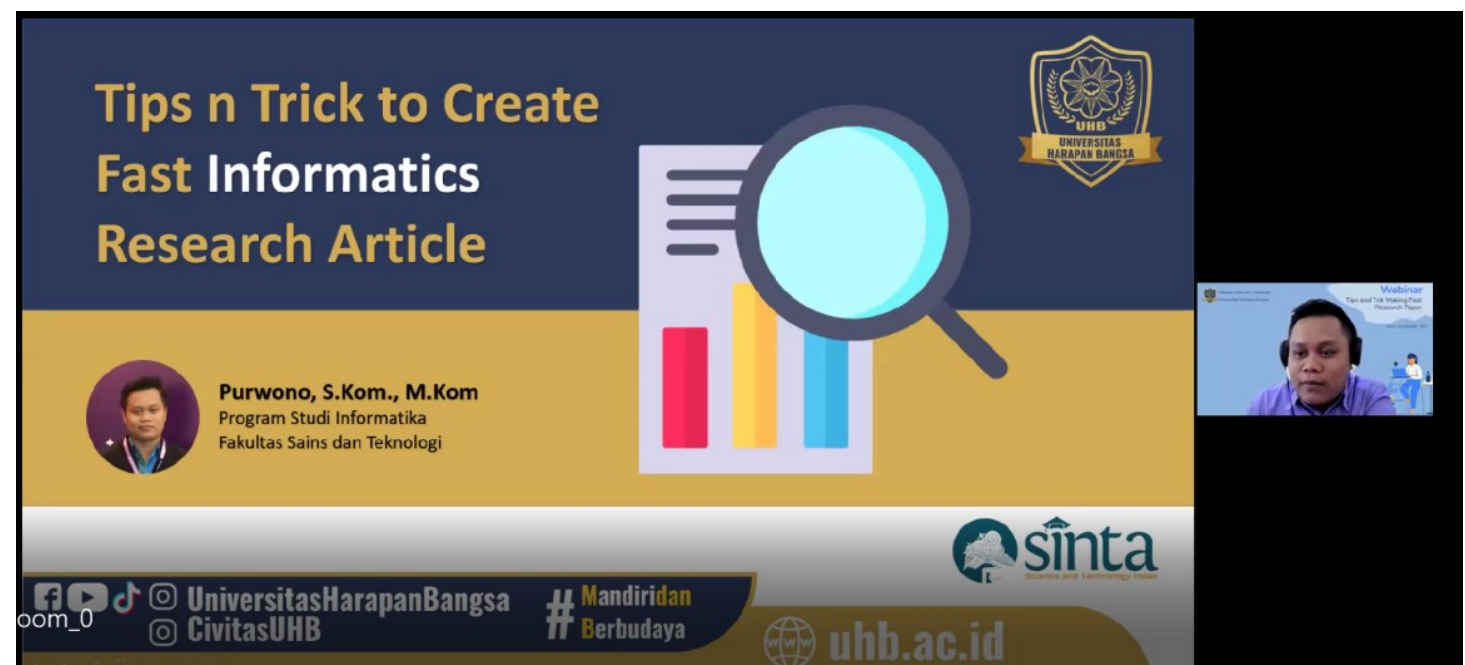

Gambar 3. Pemaparan Materi

\subsection{Evaluasi}

Proses Evaluasi yang dilakukan oleh pengabdi untuk menilai bahwa tingkat keberhasilan pengabdian ini. Parameter yang digunakan yaitu respon peserta dengan mengisi sebuah angket yang dikirimkan oleh panitia webinar melalui link. Respon positif atas penyelenggaraan dari peserta terhadap webinar juga dapat dilihat dari aktivitas tanya jawab. Pengukur kegiatan pengabdian dilakukan menggunakan google form dengan menyebar link kuisoner denga nisi pada gambar 4. 


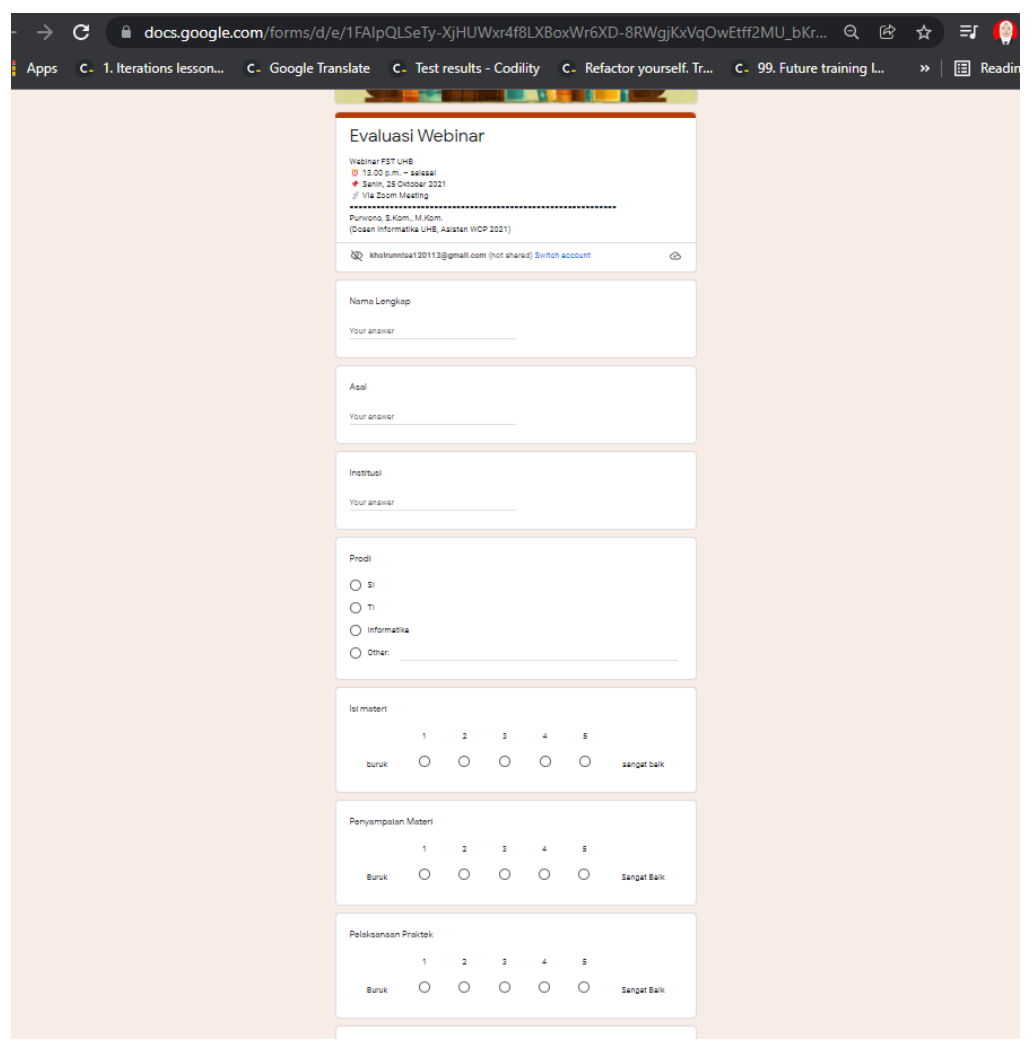

Gambar 4. Evaluasi Webinar

Berdasarkan evaluasi kegiatan yang dilaksanakan oleh tim pengabdian dapat dilihat pada tabel 2 , menyatakan bahwa peserta sangat puas dengan kegiatan webinar.

Tabel 2. Hasil Angket Evaluasi

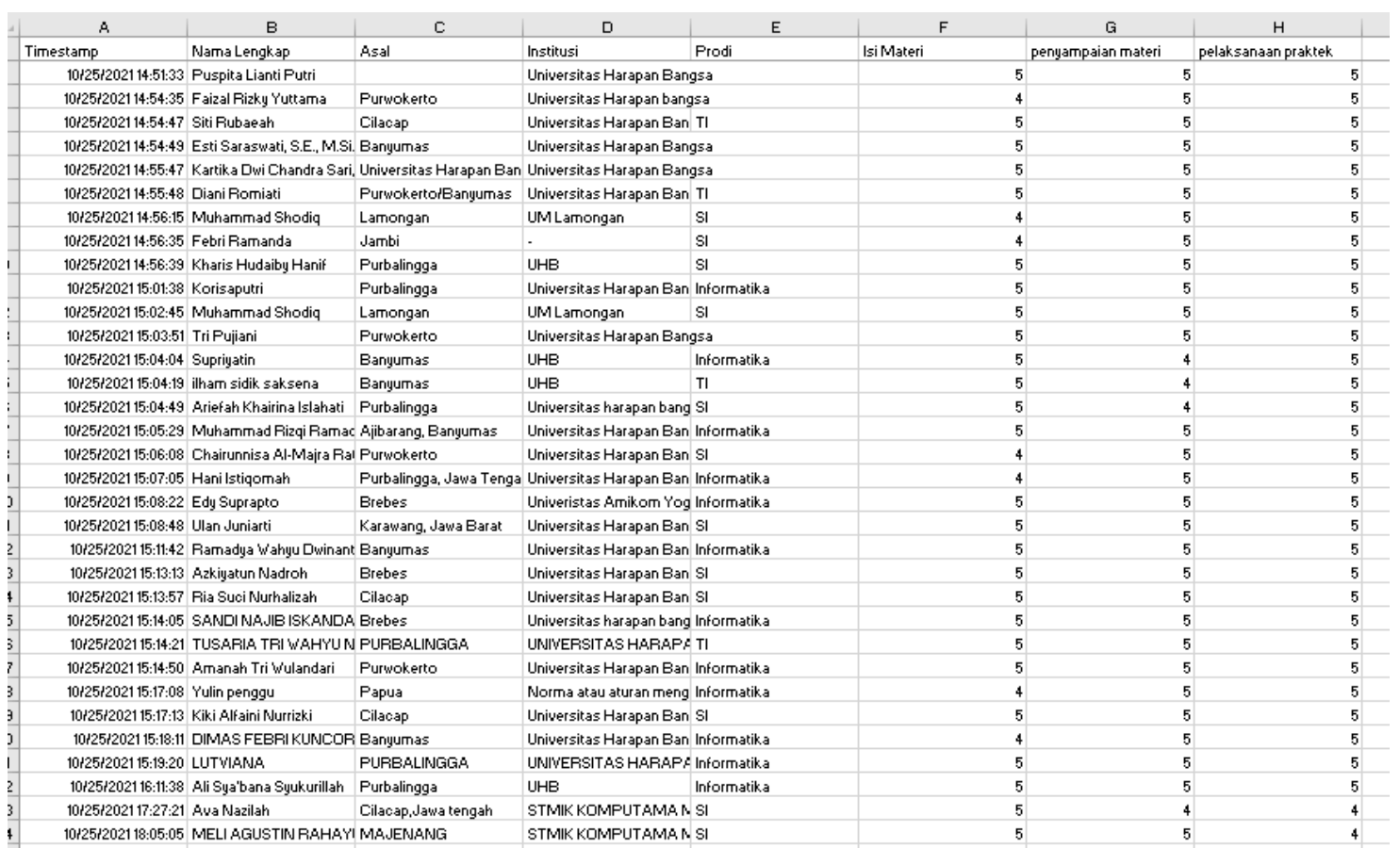

Perhitungan hasil angket dilakukan menggunakan rumus prosentasi kuisoner menurut (Sugiyono, 2008)

$$
P=f / n \times 100
$$


Keterangan :

$\mathrm{P} \quad=$ hasil prosentase

$\mathrm{F} \quad=$ frekuensi dari setiap jawaban angket

$\mathrm{N}=$ jumlah responden

Dari perhitungan dengan menggunakan rumus diatas diperoleh bahwa prosentase yang menyatakan sangat puas dengan pelatihan ini rata-rata yaitu $87,78 \%$ dan menyatakan puas rata-rata adalah $12,22 \%$ dapat dilihat pada gambar 5 grafik dibawah ini.

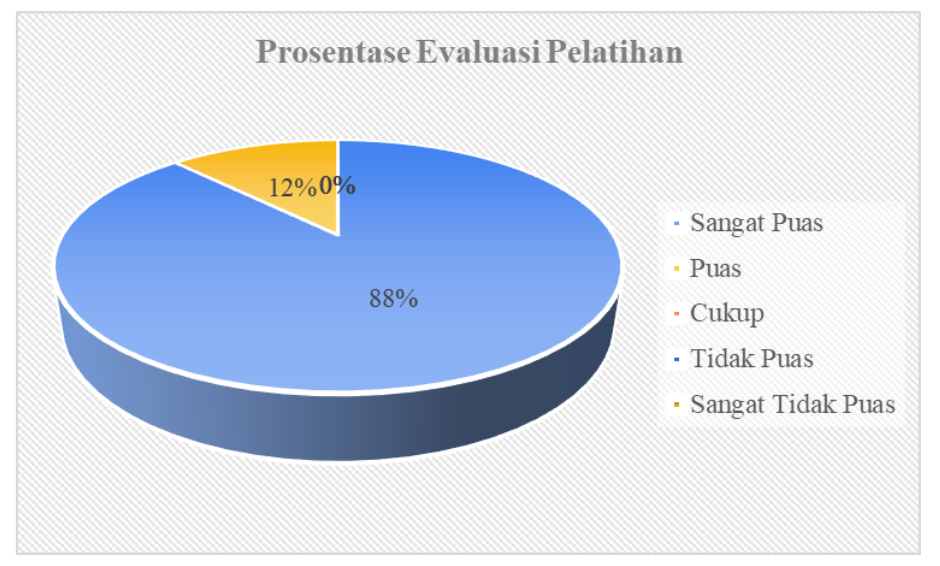

Gambar 5. Grafik Evaluasi

\section{KESIMPULAN}

Hasil dari pengabdian masyarakat ini dapat disimpulkan diantaranya: (1) Pemahaman tentang penulisan artikel ilmiah dengan tips dan trik melalui zoom yang diberikan kepada tenaga pengajar dan mahasiswa dapat memberikan pengetahuan tambahan mengenai penulisan serta publikasi ilmiah. (2) Setelah mengikuti pelatihan dan mengimplementasikan peserta menyatakan sangat puas dengan diselenggarakannya pelatihan ini terbukti dari hasil evalusi rata-rata adalah $88,78 \%$

\section{SARAN}

Saran yang dapat diberikan adalah perlu adanya pelatihan berkelanjutan khususnya pada penulisan jurnal internasional sehingga dapat meningkatnya jumlah publikasi setiap tenaga pengajar berindex scopus.

\section{DAFTAR PUSTAKA}

Butsi, F. I., \& Nasution, A. (2017). Pelatihan Tips Dan Trik Submit Artikel Ilmiah Di Jurnal Berbasis Online. Amaliah: Jurnal Pengabdian Kepada Masyarakat, 1(1), 49-51. https://doi.org/10.32696/ajpkm.v1i1.16

Darmalaksana. (2017). Riset Berbasis Outcome : Jurnal Riset Dan Inovasi, 1-10.

Darmalaksana, W., \& Suryana, Y. (2018). Korespondensi Dalam Publikasi Ilmiah. Jurnal Perspektif, 1(2), 1-8. https://doi.org/10.15575/jp.v1i2.10

Fitria, T. N. (2021). Pelatihan Penulisan Artikel Ilmiah dari Skripsi dan Tesis Untuk Mahasiswa Serta Cara Publikasinya ke Jurnal Nasional. Jurnal Abdaya, 1(September), 6-13.

Ginting, Sri Dinanta Beru, \& Basyir, M. (2021). Dosen Politeknik Negeri Lhokseumawe. Jurnal Bahasa Indonesia Prima, 23(1), 120-128.

Harahap, A., \& Yunita, W. (2021). Pelatihan Penulisan Artikel Ilmiah Berbasis Penelitian Untuk Jurnal Nasional Dan Internasional Bagi Guru Bahasa Inggris Sekolah Menengah Pertama (Smp) Di Bengkulu Tengah. 27(2502-7220), 181-185.

Nasution, M. K. M. (2016). Karya Ilmiah Dosen \& Mahasiswa. Harian Waspada, March 2016, 1-2. 
https://doi.org/10.13140/RG.2.2.17770.82888

Pribadi, B. A., \& Delfy, R. (2015). Implementasi Strategi Peta Konsep (Concept Mapping) Dalam Program Tutorial Teknik Penulisan Artikel Ilmiah Bagi Guru. Jurnal Pendidikan Terbuka Dan Jarak Jauh, 16(2), 76-88. http://jurnal.ut.ac.id/index.php/jptjj/article/view/316

Rohmah, N., \& Huda, M. A. (2016). Strategi Penigkatan Kemampuan Dosen dalam Penulisan Karya Tulis Ilmiah.(Kabupaten Lamongan). Jurnal Pendidikan, 1(7), 1312-1322.

Sugiyono. (2008). Metode Penelitian Kuantitatif Kualitatif dan R\&D. ALFABETA.

Udil, P. A. (2021). Pelatihan penulisan artikel ilmiah penelitian tindakan kelas untuk publikasi pada jurnal illmiah. Jurnal Nasional Pengabdian Masyarakat, 2(1), 21-27. https://doi.org/10.47747/pengabdiankepadamasyarakat.v2i1.257 